\title{
A Review of the Evidence for Using Bedaquiline (TMC207) to Treat Multi-Drug Resistant Tuberculosis
}

Gregory J. Fox • Dick Menzies

To view enhanced content go to www.infectiousdiseases-open.com

Received: May 31, 2013 / Published online: August 2, 2013

(c) The Author(s) 2013. This article is published with open access at Springerlink.com

\section{ABSTRACT}

Existing therapies for multi-drug resistant tuberculosis (MDR-TB) have substantial limitations, in terms of their effectiveness, side-effect profile, and complexity of administration. Bedaquiline is a novel diarylquinoline antibiotic that has recently been investigated as an adjunct to existing therapies for MDR-TB. Currently, limited clinical data are available to evaluate the drug's safety and effectiveness. In two small randomized-controlled clinical studies, bedaquiline given for 8 or 24 weeks has been shown to improve surrogate microbiological markers of treatment response, but trials have not yet evaluated its impact on clinical failure and relapse. Safety concerns include an

\section{G. J. Fox · D. Menzies ( $ه)$}

Respiratory Epidemiology and Clinical Research Unit, Montreal Chest Institute, 3650 St. Urbain Street, Montreal, PQ H2X 2P4, Canada e-mail: dick.menzies@mcgill.ca

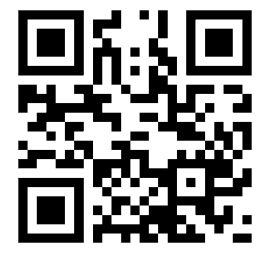

Enhanced content for this article is

available on the journal web site:

www.infectiousdiseases-open.com increased mortality in the bedaquiline arm of one study, an increased incidence of QT segment prolongation on electrocardiogram, and hepatotoxicity. Until further research data are available, the use of bedaquiline should be confined to settings where carefully selected patients can be closely monitored.

Keywords: Antitubercular agents; Bedaquiline; Drug-resistant tuberculosis; Extensively drugresistant; Multidrug-resistant tuberculosis; Tuberculosis; TMC207

\section{INTRODUCTION}

Tuberculosis (TB) is an airborne infectious disease caused by $M$. tuberculosis, with an incidence of almost nine million cases each year worldwide [1]. Standard treatment regimens are highly effective for patients with drug-sensitive disease, although they require a combination of four anti-TB drugs for 2 months, followed by two drugs for an additional 4-6 months [2]. However, treatment outcomes are substantially worse for patients with disease that is resistant to isoniazid and 
rifampin-the two key drugs of the standard regimens [3].

Multi-drug-resistant (MDR)-TB is caused by bacilli, which are resistant at least to rifampicin and isoniazid [1], and occurs in $3.7 \%$ of all newly diagnosed cases and $20 \%$ of previously treated cases [1], although in some settings the prevalence is much higher. Treatment of MDRTB is substantially more complex, more costly, and less effective than standard therapy, typically requiring the use of at least six antiTB drugs, including an injectable agent and a total treatment duration of more than 18 months [4]. Extensively drug-resistant (XDR)-TB, defined as MDR-TB with resistance to a fluoroquinolone and a second-line injectable antibiotic, requires even more lengthy and complex treatment. Drugs used to treat both MDR- and XDR-TB are often poorly tolerated and associated with high rates of adverse events. Treatment is successful in only $50-80 \%$ of cases of MDR-TB [5-7], and less than $50 \%$ of cases for XDR-TB [8]. In light of the limitations of existing therapy, the Global Plan to Stop TB has highlighted the importance of developing additional drug regimens that are effective against drug-resistant disease [9].

Bedaquiline (previously known as TMC207) is a novel member of the diarylquinoline class of anti-TB drugs. Following promising results in a number of pre-clinical and clinical studies, the drug was approved in 2012 by the US Food and Drug Administration (FDA) for use in the treatment of pulmonary MDR-TB [10]. An expert group convened by the World Health Organization has also released interim policy recommendations regarding the use of bedaquiline as a part of treatment for pulmonary MDR-TB [11]. However, concerns have been raised about the drug's effectiveness and safety $[12,13]$.
This review evaluates the available clinical evidence for the use of bedaquiline to treat drug-resistant TB.

\section{METHODS}

A literature search was performed using PubMed, applying the search terms "bedaquiline" or "TMC207" and "tuberculosis", for studies published up to April 1, 2013. The full-text of articles was reviewed. The website of the US FDA was also searched for available data about bedaquiline, and data from publically available reports and submissions were included in this review. For comparisons between bedaquiline and placebo groups, if $P$ values were not stated in the publication then they were calculated using Pearson's $\chi^{2}$ test or Fisher's exact test. For studies where follow-up data were incomplete, outcomes were included up to the stated cut-off reporting dates.

\section{MECHANISM OF ACTION}

Bedaquiline is a diarylquinoline compound that specifically inhibits the proton pump of mycobacterial adenosine triphosphate (ATP) synthase, which is essential for mycobacterial energy generation $[14,15]$. The drug is structurally and mechanistically different than fluoroquinolone antibiotics, and other related quinoline classes of drugs. This means that antibiotic resistance to fluoroquinolones, which are a part of standard treatment of MDR-TB, does not also confer resistance to bedaquiline [14].

Bedaquiline has bactericidal activity in vitro against $M$. tuberculosis as well as other mycobacterial species [14]. It inhibits both actively replicating and non-replicating mycobacteria, with one study showing 
inhibition of dormant cells in latent $\mathrm{TB}$ infection at a low concentration [16]. Mycobacterial susceptibility to the drug is unaltered in the presence of resistance to other anti-TB drugs, including isoniazid, rifampicin, ethambutol, streptomycin, ethambutol, and moxifloxacin [14].

\section{ADMINISTRATION, PHARMACOKINETICS, AND PHARMACODYNAMICS}

Bedaquiline is given orally, reaching peak concentration $5 \mathrm{~h}$ after administration [14]. Eating food at the same time as taking the drug doubles its bioavailability compared with taking it when fasting [17]. Consequently, bedaquiline should be given with food.

The active drug undergoes oxidation primarily in the liver, by cytochrome P3A4 (CYP3A4), to a less active metabolite $N$ monodesmethyl (M2) that has a three- to sixfold lower antimicrobial effect than bedaquiline [17]. Hence, co-administration of drugs that potentiate CYP3A4, such as rifampicin, is likely to reduce the plasma concentrations of the bedaquiline and potentially reduce its effectiveness. Conversely, drugs that inhibit these enzymes, such as protease inhibitors, macrolide antibiotics, and azole antifungals, may increase systemic concentrations and the likelihood of adverse events. The primary metabolite of bedaquiline, M2, is removed mainly in the stool, with only $1-4 \%$ removed in the urine [15]. Although patients with advanced renal impairment were excluded from Phase 1 and 2 studies, mild-to-moderate renal impairment (median creatinine clearance $108 \mathrm{~mL} / \mathrm{min}$, range $39.8-227 \mathrm{~mL} / \mathrm{min}$ ) did not affect the drug's pharmacokinetics [17]. Bedaquiline has a multi-phasic distribution and an effective half-life of $24 \mathrm{~h}$, which is substantially longer than most other antituberculosis drugs $[14,15]$.

Importantly, the drug has a very long terminal elimination half-life of 5.5 months [17], owing to a combination of a long plasma half-life, high tissue penetration (particularly the organs affected by TB), and long half-life in tissues [14]. While this means that less frequent dosing may be feasible, adverse events may also be prolonged after drug cessation.

The initial safety studies of bedaquiline found that its pharmacokinetics was not influenced by age, sex, body weight, and human immunodeficiency virus (HIV)-coinfection in the absence of anti-retroviral treatment [17]. In these studies, subjects of black ethnicity had lower concentrations of bedaquiline than other races. Of note, in light of this finding, bedaquiline did not improve treatment outcomes in one sub-group of people of African ancestry in a recent clinical trial [17].

The pharmacokinetics of bedaquiline has only been studied in adults from 18-65 years, and not yet in pediatric or elderly populations. Phase 2 studies suggest that there is no need to adjust dose for patients with hepatic or renal impairment, although caution should be used in patients with severe renal or hepatic disease [18].

\section{DOSING AND ADMINISTRATION}

Bedaquiline is currently available as an oral, uncoated, immediate-release tablet which contains $100 \mathrm{mg}$ of bedaquiline-free base [15]. The recommended dose, as a part of combination therapy for pulmonary MDR-TB, is $400 \mathrm{mg}$ daily for 2 weeks, followed by $200 \mathrm{mg}$ three times per week. Regimens used in published studies have given the drug as a part 
of MDR-TB therapy for up to 24 weeks in total $[15,18,19]$.

The published pre-clinical and Phase 1 clinical studies of bedaquiline are summarized in Tables 1 [14-16, 20-54] and 2 [15, 55-60].

\section{CLINICAL EVIDENCE FOR THE EFFICACY OF BEDAQUILINE IN MDR-TB}

The available data evaluating efficacy of bedaquiline are limited to one published Phase 2 clinical study of 47 patients [14, 18, 19]. Data from two other Phase 2 studies have been made available by the manufacturer in its public

Table 1 Summary of pre-clinical studies of bedaquiline

\begin{tabular}{|c|c|}
\hline Subject of study & References \\
\hline Chemical synthesis & {$[20]$} \\
\hline $\begin{array}{l}\text { Study of drug structure and } \\
\text { mechanism }\end{array}$ & {$[21-29]$} \\
\hline $\begin{array}{l}\text { Anti-tuberculosis resistance } \\
\text { to bedaquiline in vitro }\end{array}$ & {$[30,31]$} \\
\hline $\begin{array}{l}\text { Pharmacokinetics/ } \\
\text { pharmacodynamics in } \\
\text { animal studies (such as } \\
\text { mice studies) }\end{array}$ & {$[15,32]$} \\
\hline $\begin{array}{l}\text { Drug interaction studies in } \\
\text { animals }\end{array}$ & {$[33,34]$} \\
\hline $\begin{array}{l}\text { Bactericidal efficacy studies } \\
\text { against } M \text {. tuberculosis in } \\
\text { animal studies }\end{array}$ & {$[14,15,33-43]$} \\
\hline \multirow[t]{2}{*}{$\begin{array}{l}\text { Bactericidal effect against } M \text {. } \\
\text { tuberculosis in vitro }\end{array}$} & $\begin{array}{l}\text { Active } M . \text { tuberculosis } \\
{[15,44-48]}\end{array}$ \\
\hline & $\begin{array}{l}\text { Latent TB infection } \\
{[14,16,49,50]}\end{array}$ \\
\hline $\begin{array}{l}\text { Bactericidal effect against } \\
\text { other mycobacteria }\end{array}$ & $\begin{array}{l}\text { [51] (M. avium), [52] and } \\
\text { [53] (M. leprae) [16], } \\
\text { (M. smegmatis), [54] (non- } \\
\text { tuberculous mycobacteria) }\end{array}$ \\
\hline
\end{tabular}

Table 2 Summary of Phase 1 clinical studies of bedaquiline

\begin{tabular}{ll}
\hline Subject of study & References \\
\hline Pharmacokinetics/pharmacodynamics & {$[15,55]$} \\
Safety and tolerability & {$[55]$} \\
Dose ranging & {$[56]$} \\
Pharmacokinetic drug interactions & {$[57]$} \\
Modeling study & {$[58]$} \\
Bactericidal effect & {$[55,59,60]$} \\
\hline
\end{tabular}

submission to the US FDA $[15,17]$. In these trials, summarized in Figs. 1 [18, 19], 2 [17], and 3 [17], the drug was given for a maximum of 24 weeks. Time to culture conversion at 8,24 , 72 , and 104 weeks was the reported end-points. The data from these studies describing the impact of bedaquiline upon clinical end points, such as the rate of cure at 104 weeks, have not yet been published.

\section{The First Phase 2 Study of Bedaquiline}

In the one randomized controlled trial on efficacy for which published data are available [14, 18, 19], patients aged 18-65 years with MDR-TB from six centers in South Africa were enrolled. In total, 47 patients were randomized to either bedaquiline or a placebo for 8 weeks (Table 3) [17-19]. Both groups also took an optimized background regimen (OBR) comprising standard treatment for MDR-TB, which was considered to be most appropriate by treating clinicians in that setting. Treatment outcomes have been published in three separate reports - for 8 weeks [18], 24 weeks [19], and 104 weeks [19] of follow-up.

The primary end point of this study, time to culture conversion at 8 weeks, was significantly shorter for patients taking bedaquiline than for those taking an OBR with placebo (hazard ratio 


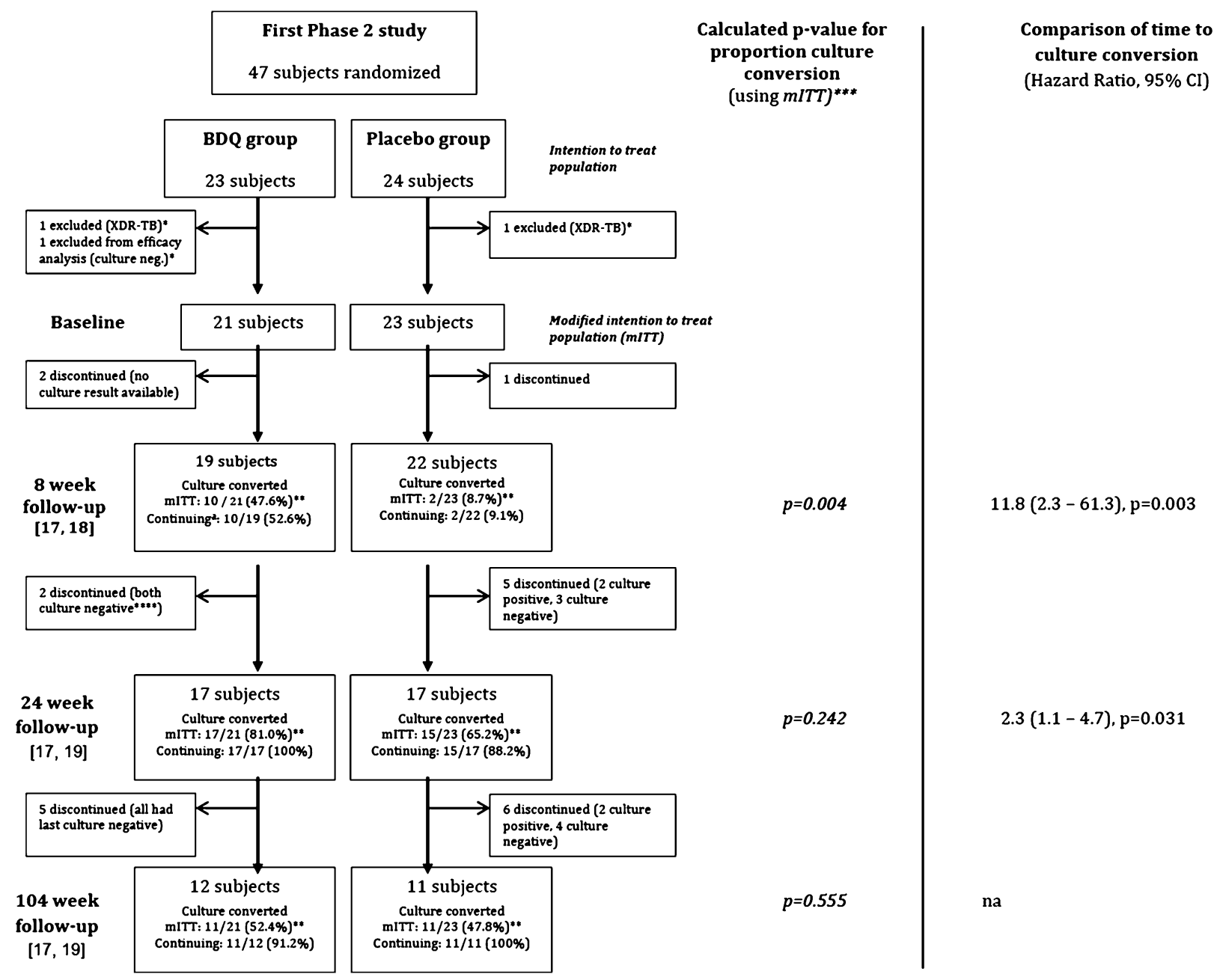

Fig. 1 Summary of first Phase 2 study. *Subjects were excluded from the mITT analysis, as subjects did not meet inclusion criteria despite being randomized. ${ }^{* *}$ Calculations based upon mITT analysis. ${ }^{* *} P$ values calculated using uncorrected $\chi^{2}$ statistic with data from the modified intention to treat analysis. ${ }^{* * * *}$ Culture results in discontinuing patients reported for time of last available culture

[HR] $11.8 \quad[2.3,61.3], \quad P=0.0034), \quad$ with adjustment for cavitation and study center) [18]. In addition, patients taking bedaquiline plus OBR had significantly greater proportion of culture conversion at 8 weeks compared to OBR plus placebo ( $47.6 \%$ versus $8.7 \%$, respectively).

Culture conversion at 24 weeks was also significantly greater among patients taking bedaquiline compared to OBR with placebo
[19]. Italicized $P$ values were calculated from data in papers. ${ }^{a}$ Continuing patients: refers only to patients continuing follow-up, excluding subjects withdrawing prior to stated time points ( 8 weeks, 24 weeks, and 104 weeks). Source: data from $[18,19]$. $B D Q$ bedaquiline, mITT modified intent to treat, na not available, $X D R-T B$ extensively drugresistant tuberculosis

(81.0\% versus $65.2 \%$ ) [19], and time to culture conversion at 24 weeks was also shorter (HR 2.3, 95\% CI 1.1, 4.7) [19]. When an intention to treat analysis was performed for all subjects up to 104 weeks, the rate of microbiological conversion was not significantly different between the bedaquiline group and placebo (52.4\% versus $47.8 \%, P=0.76$ ) [19]. This is due in part to the high drop-out rates seen in both 


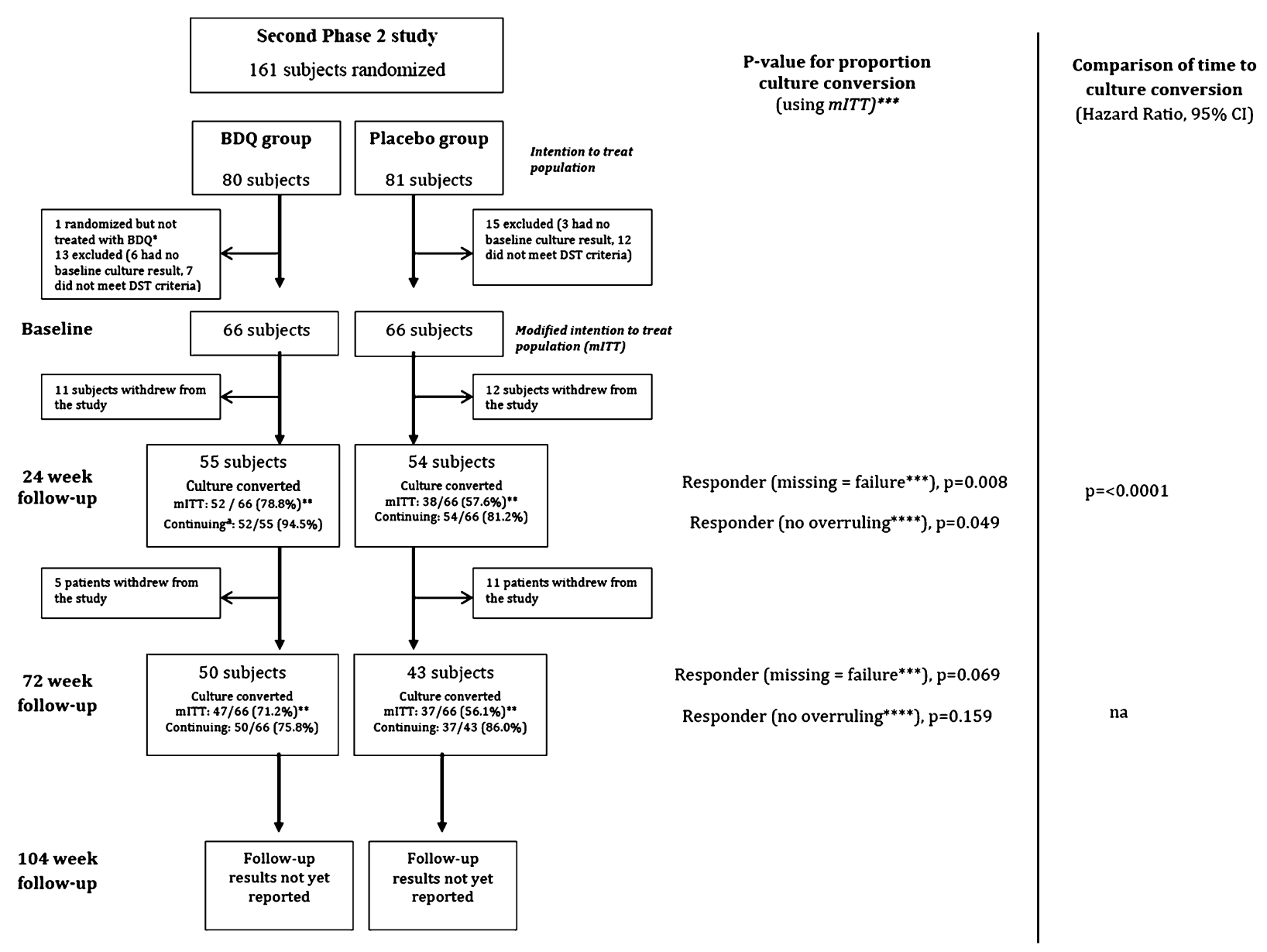

Fig. 2 Summary of second Phase 2 study. ${ }^{*}$ Excluded from mITT analysis. Subject was excluded after being randomized, before receiving bedaquiline, based on an adverse event. ${ }^{* *}$ Calculations based upon mITT analysis. ${ }^{* * *} \mathrm{~A}$ subject was considered responder (missing $=$ failure) if at least 2 cultures from sputa collected at least 25 days apart were MGIT culture negative (as well as all intermediate cultures), this culture negativity was not followed by a confirmed positive MGIT culture (or a single positive sputum result after which the subject completed the trial), and the subject did not discontinue up to the time point being analyzed. ${ }^{* * *} \mathrm{~A}$ subject was considered responder (no

arms (44\% drop-out in the bedaquiline group and $54 \%$ in the placebo group).

The study was not powered to detect relapse, although at the end of the study two members of the bedaquiline group and four members of the control group had experienced treatment failure $[17,61]$. overruling) if at least 2 cultures from sputa collected at least 25 days apart were MGIT culture negative (as well as all intermediate cultures) and this culture negativity was not followed by a confirmed positive MGIT culture (or a single positive sputum result after which the subject completed or discontinued the trial) up to the time point being analyzed. ${ }^{a}$ Continuing patients: refers only to patients continuing follow-up, excluding subjects withdrawing prior to stated time points ( 24 weeks, 72 weeks, and 104 weeks). Source: data from [17]. $B D Q$ bedaquiline, $D S T$ Drug susceptibility testing, MGIT Mycobacteria Growth Indicator Tube, mITT modified intention to treat, $\mathrm{Na}$ not available

\section{The Second Phase 2 Study of Bedaquiline}

Data from a second Phase 2 study of the clinical effectiveness of bedaquiline (Study C208, Stage 2) have been presented in a public submission to the US FDA, although the results have not yet appeared in a peer-reviewed publication. This 


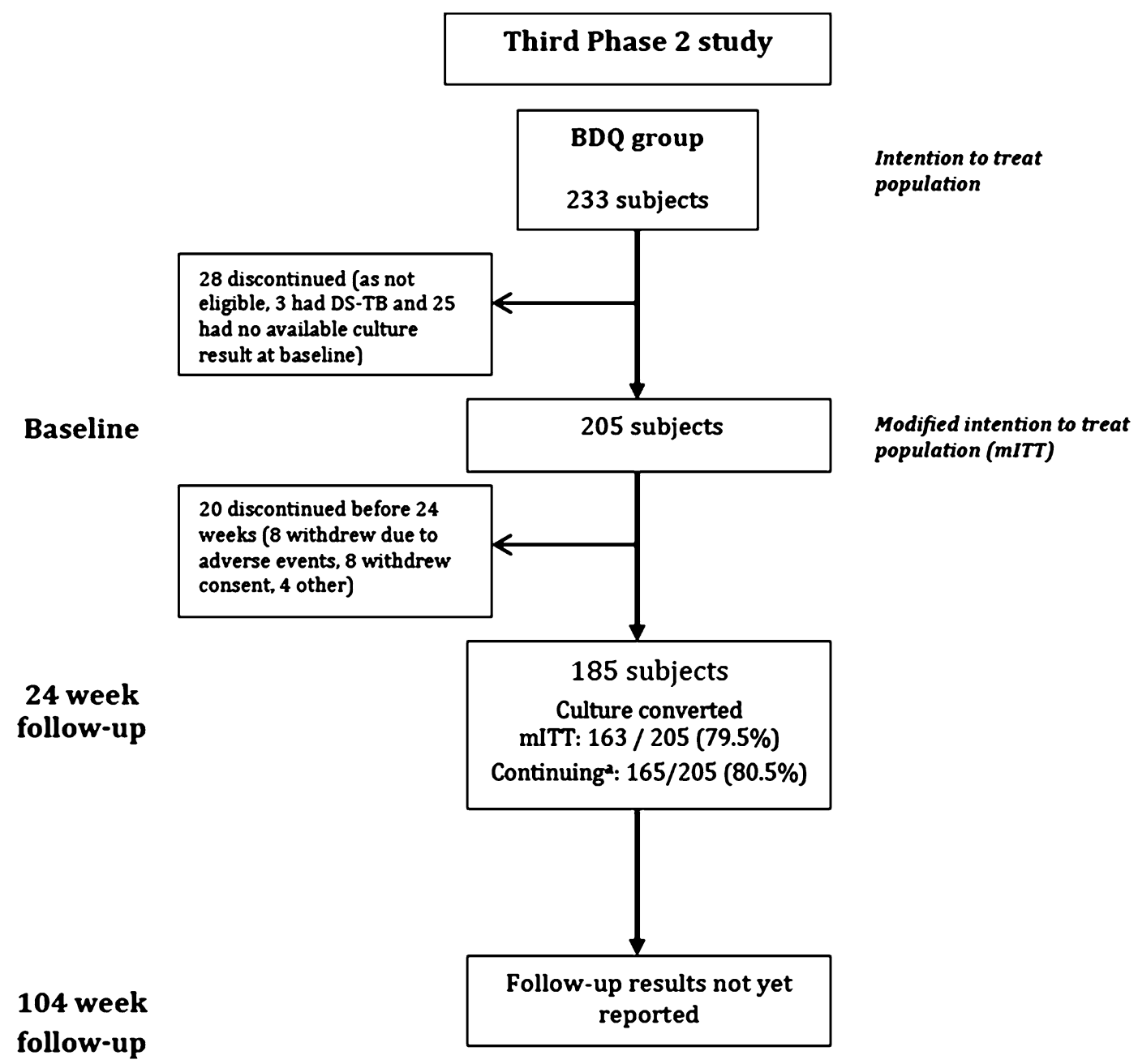

Fig. 3 Summary of third Phase 2 study data from [17]. $B D Q$ bedaquiline, $D S$ drug susceptible, mITT modified intention to treat, $T B$ tuberculosis. ${ }^{a}$ Continuing patients:

study enrolled 161 patients with MDR-TB, at 15 study sites in eight countries [17]. Patients were randomized either to 24 weeks of bedaquiline with a five-drug OBR or the OBR plus placebo. OBR was continued after stopping bedaquiline or placebo. The primary end point was time to sputum culture conversion at 24 weeks (Table 4) $[15,17]$. The two groups were comparable.

A modified intention to treat analysis showed that culture conversion during the first 24 weeks was faster in the group with bedaquiline than the control group (83 days versus 125 days, HR 2.44 [95\% CI 1.57, 3.80], refers only to patients continuing follow-up, excluding subjects withdrawing prior to stated time points (24 weeks)

$P<0.0001)$ [17], but there was no significant difference between the treatment groups in this outcome at 72 weeks $(P=0.069)$ [17]. During the 2-year follow-up, three patients in the bedaquiline group and seven in the control group experienced treatment failure.

\section{Third Phase 2 Study of Bedaquiline}

Preliminary results are also available from a third, uncontrolled study of 233 patients enrolled at 33 sites in Asia, South Africa, Eastern Europe, and South America (Study 


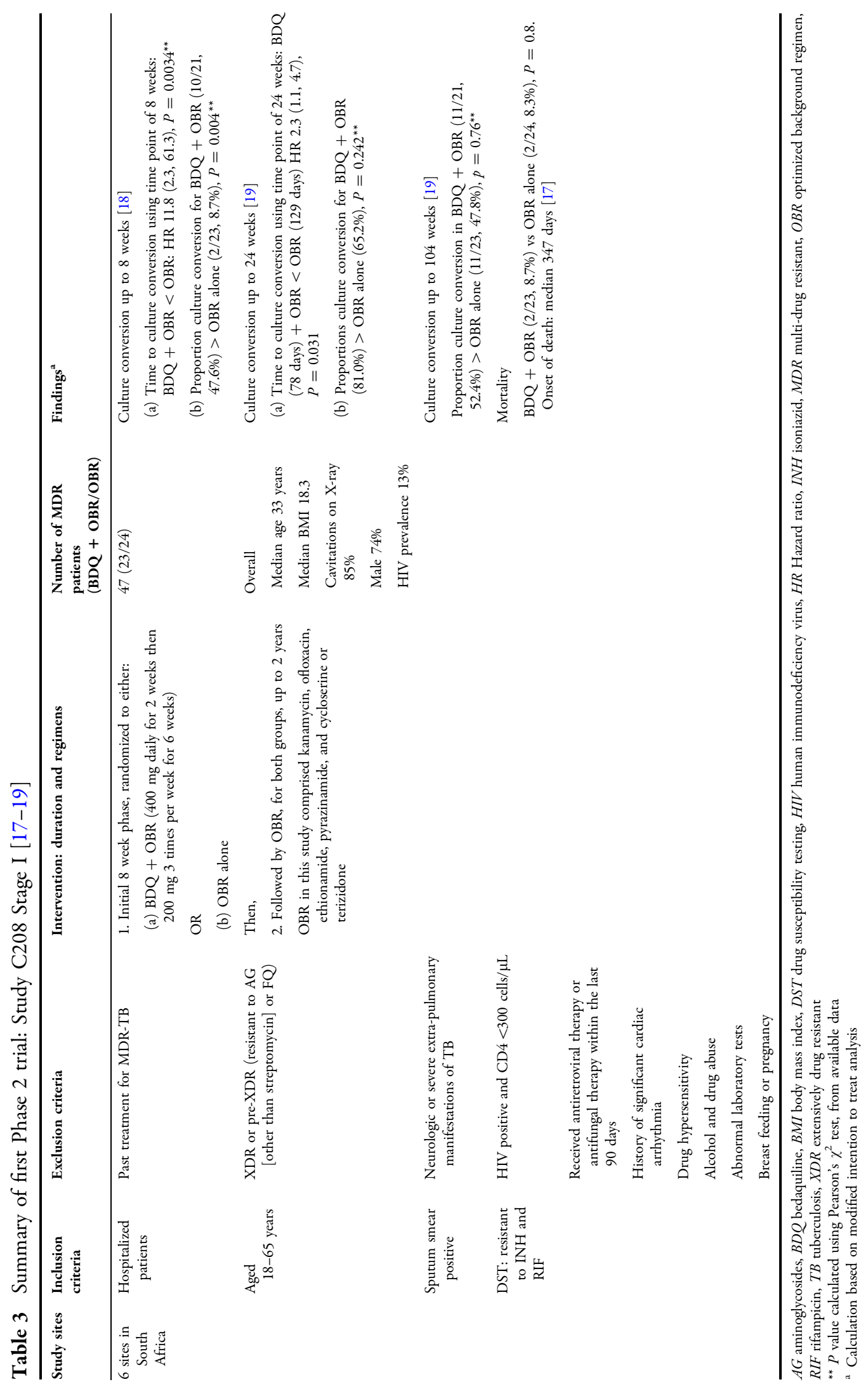




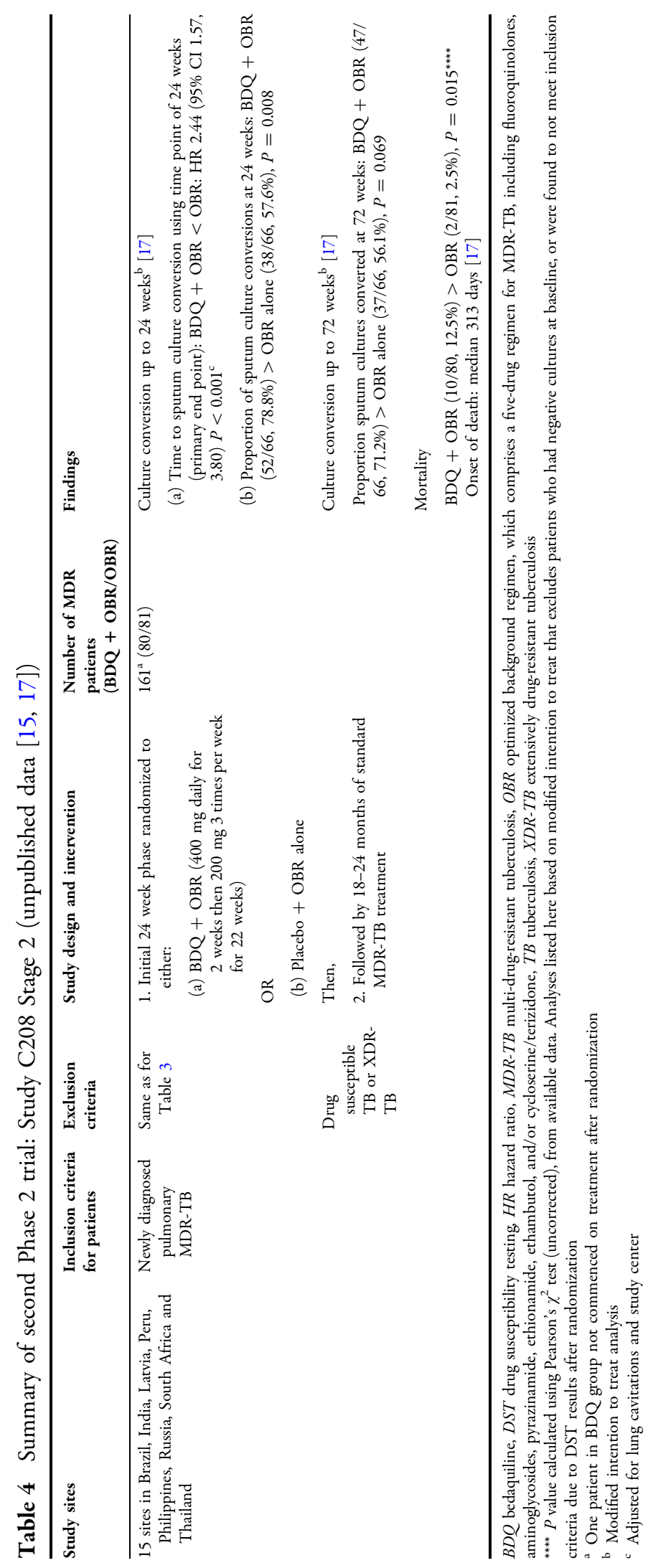




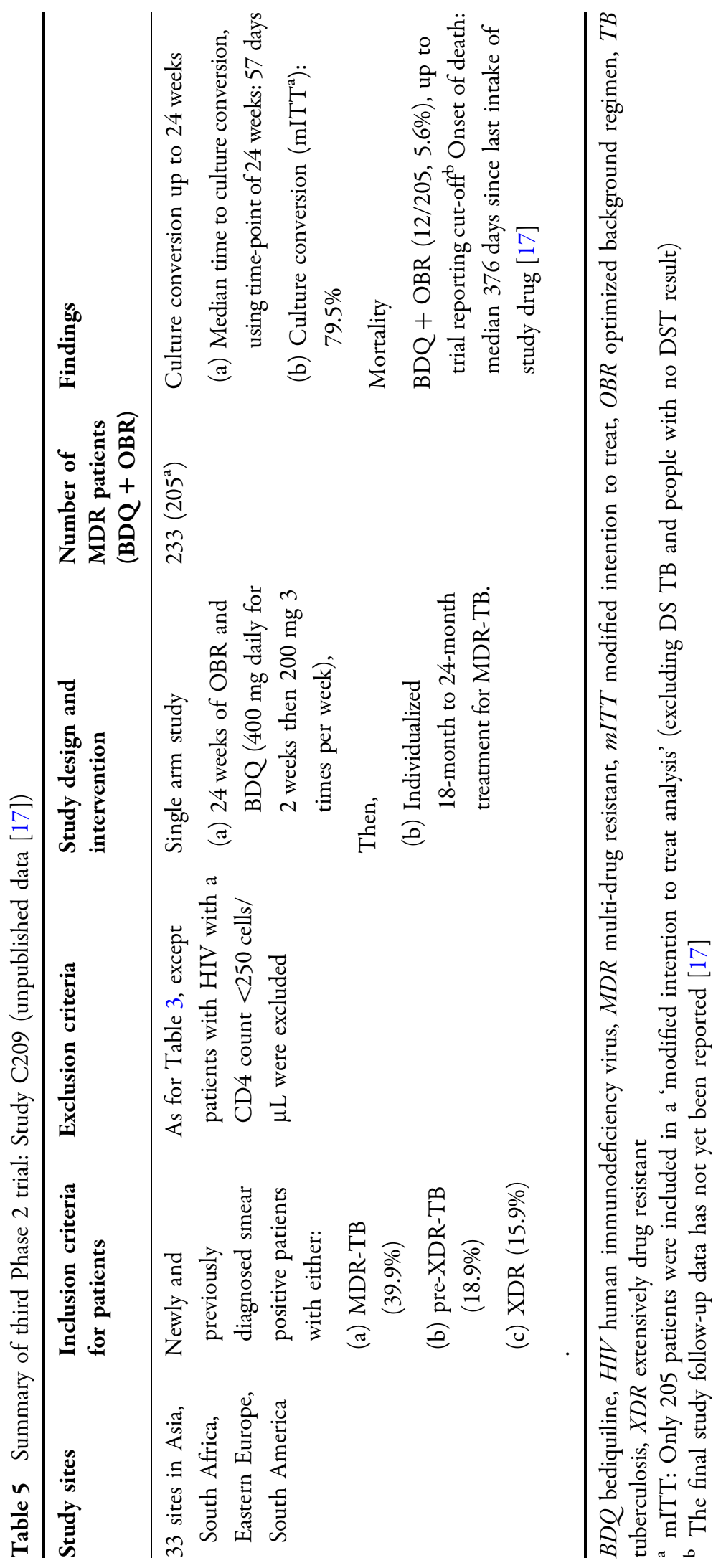


C209). These data also appeared only in the US FDA submission [17]. This study gave bedaquiline to patients with newly diagnosed or previously treated patients with either MDRTB or XDR-TB (where the isolate was sensitive to at least three drugs other than bedaquiline). Time to culture conversion at 24 weeks was the primary outcome measure (Table 5) [17]. The mean time to culture conversion was 57 days [17]. A modified intention to treat analysis at 24 weeks showed that the rate of culture conversion was $79.5 \%$.

\section{CLINICAL EVIDENCE FOR SAFETY OF BEDAQUILINE}

Pooled safety data are available from the first and second Phase 2 studies [17]. Overall, 96.1\% of 102 subjects receiving bedaquiline and $95.2 \%$ of the 105 subjects receiving placebo reported at least one adverse event [17]. Adverse events with a prevalence of more than $10 \%$ in the pooled analysis of the first and second Phase 2 studies are presented in Table $6[17,62]$. There was no overall difference in the incidence of these adverse events between groups, after accounting for multiple testing. In the two studies, $27.5 \%$ of subjects taking bedaquiline and $22.9 \%$ of subjects taking placebo experienced grade 3 or 4 adverse events of any kind [17]. The most common of these events was hyperuricemia, which occurred in $10.8 \%$ of patients taking bedaquiline and $13.3 \%$ of patients taking placebo.

The prevalence of drug-related hepatic disorders was significantly higher in those taking bedaquiline (8.8\% in bedaquiline, $1.9 \%$ in placebo, $P=0.03)$, with increases in alanine transferase (ALT) observed in $5.0 \%$ of bedaquline and in $1.0 \%$ of subjects taking placebo [17]. Two patients taking bedaquiline in the pooled Phase 2 studies had grade 3 or 4 liver function test abnormalities close to the time of death [17]. The first death, attributed to hepatitis and hepatic cirrhosis, occurred approximately 3 months after the last administered dose of the drug, but pretreatment transaminases and bilirubin were normal, so it is possible the hepatic failure was bedaquiline-related. A second patient died 513 days after the last dose of bedaquiline, following liver failure and sepsis. Pretreatment liver function was also normal in this patient, and it is possible that the deterioration in liver function was related to the drug.

Another patient developed liver injury after taking bedaquiline, with more than a three-fold increase in aspartate aminotransferase (AST) and more than a two-fold increase in bilirubin. It is possible that hepatotoxicity in this patient was caused by bedaquiline; however, concomitant alcoholic hepatitis and use of other hepatotoxic anti-TB medications may also explain the metabolic derangements [17]. Overall, the authors conclude that bedaquiline was possibly responsible for serious liver toxicity among patients in the Phase 2 studies [16], and suggest careful monitoring, particularly in patients with pre-existing liver disease and/or regular alcohol use.

Acute pancreatitis occurred in two patients taking bedaquiline, but no patients in the placebo group. No events of rhabdomyolysis or myopathy were reported.

Bedaquiline prolongs the corrected QT interval (QTc). Close monitoring identified a mean increase in QTc of $15.4 \mathrm{~ms}$ over the first 24 weeks for patients taking bedaquiline, and $7.7 \mathrm{~ms}$ among placebo patients in the first and second studies [17]. The QTc was between $450 \mathrm{~ms}$ and $500 \mathrm{~ms}$ for $22.5 \%$ of patients taking bedaquiline and $6.7 \%$ of patients taking placebo in the first two studies. In the third 
Table 6 Adverse events of any grade, reported in at least $10 \%$ of subjects in the first and second Phase 2 studies

\begin{tabular}{|c|c|c|c|c|}
\hline & \multicolumn{2}{|l|}{ Up to 24-week follow-up } & \multicolumn{2}{|l|}{ All follow-ups } \\
\hline & $\begin{array}{l}\text { In patients taking BDQ } \\
\text { for } 24 \text { weeks } \\
n=79 \\
n(\%)\end{array}$ & $\begin{array}{l}\text { In patients taking } \\
\text { placebo for } 24 \text { weeks } \\
n=81 \\
n(\%)\end{array}$ & $\begin{array}{l}\text { In all patients } \\
\text { taking BDQ } \\
n=102 \\
n(\%)\end{array}$ & $\begin{array}{l}\text { In all patients } \\
\text { taking placebo } \\
n=105 \\
n(\%)\end{array}$ \\
\hline Any adverse event & $77(97.5)$ & $77(95.1)$ & $98(96.1)$ & $100(95.2)$ \\
\hline Gastrointestinal disorders & $50(63.3)$ & $50(61.7)$ & $59(57.8)$ & $59(56.2)$ \\
\hline Nausea & $30(38.0)$ & $26(32.1)$ & $36(35.3)$ & $27(25.7)$ \\
\hline Vomiting & $20(25.3)$ & $21(25.9)$ & $21(20.6)$ & $24(22.9)$ \\
\hline Upper abdominal pain & $9(11.4)$ & $7(8.6)$ & $10(9.8)$ & $8(7.6)$ \\
\hline Gastritis & $6(7.6)$ & $13(16.0)$ & $6(5.9)$ & $13(12.4)$ \\
\hline Diarrhea & $3(3.8)$ & $11(13.6)$ & $6(5.9)$ & $12(11.4)$ \\
\hline Nervous system disorders & $32(40.5)$ & $21(25.9)$ & $37(36.3)$ & $24(22.9)$ \\
\hline Headache & $22(27.8)$ & $10(12.3)$ & $24(23.5)$ & $12(11.4)$ \\
\hline Dizziness & $10(12.7)$ & $10(12.3)$ & $13(12.7)$ & $12(11.4)$ \\
\hline Musculoskeletal disorders & $35(44.3)$ & $32(39.5)$ & $41(40.2)$ & $39(37.1)$ \\
\hline Arthralgia & $26(32.9)$ & $18(22.2)$ & $30(29.4)$ & $21(20.0)$ \\
\hline $\begin{array}{l}\text { Ear and labyrinth } \\
\text { disorders }\end{array}$ & $24(30.4)$ & $26(32.1)$ & $32(31.4)$ & $37(35.2)$ \\
\hline Deafness & $9(11.4)$ & $6(7.4)$ & $12(11.8)$ & $11(10.5)$ \\
\hline Tinnitus & $2(2.5)$ & $10(12.3)$ & $2(2.0)$ & $10(9.5)$ \\
\hline Respiratory disorders & $25(31.6)$ & $28(34.6)$ & $28(27.5)$ & $33(31.4)$ \\
\hline Hemoptysis & $14(17.7)$ & $9(11.1)$ & $17(16.7)$ & $13(12.4)$ \\
\hline $\begin{array}{l}\text { Infections and } \\
\text { infestations }\end{array}$ & $25(31.6)$ & $28(34.6)$ & $28(27.5)$ & $33(31.4)$ \\
\hline Chest pain & $9(11.4)$ & $6(7.4)$ & $9(8.8)$ & $8(7.6)$ \\
\hline $\begin{array}{l}\text { Skin and subcutaneous } \\
\text { tissues }\end{array}$ & $19(24.1)$ & $21(25.9)$ & $25(24.5)$ & $28(26.7)$ \\
\hline Pruritis & $10(12.7)$ & $11(13.6)$ & $12(11.8)$ & $13(12.4)$ \\
\hline Psychiatric disorders & $15(19.0)$ & $11(13.6)$ & $16(15.7)$ & $13(12.4)$ \\
\hline Insomnia & $11(13.9)$ & $9(11.1)$ & $11(10.8)$ & $10(9.5)$ \\
\hline Eye disorders & $10(12.7)$ & $14(17.3)$ & $13(12.7)$ & $15(14.3)$ \\
\hline $\begin{array}{l}\text { Blood and lymphatic } \\
\text { disorders }\end{array}$ & $8(10.1)$ & $4(4.9)$ & $9(8.8)$ & $4(3.8)$ \\
\hline $\begin{array}{l}\text { Reproductive system and } \\
\text { breast disorders }\end{array}$ & $7(8.9)$ & $10(12.3)$ & $8(7.8)$ & $13(12.4)$ \\
\hline
\end{tabular}

No significant difference was identified for any of the listed adverse events, using Fisher's exact test and correcting for multiple testing using the Sidak correction [62]. Source: Modified from [17]

$B D Q$ bedaquiline, $O B R$ optimized background regimen

a 24 weeks: includes only subjects from the second phase 2 study (Study C208 [Stage 2]). This table includes pooled data from the first and second Phase 2 studies (Study C208 [Stage 1] and C208 [Stage 2]) 
study, one patient taking bedaquiline had a QTc exceeding $500 \mathrm{~ms}$ in and nine of 233 subjects (3.9\%) had an increase of over $60 \mathrm{~ms}$. In a subgroup analysis in the third study, at the end of 24 weeks, the mean increase in QTc was greater for patients taking bedaquiline and clofazimine (32-ms increase) than for bedaquiline alone (12.3 ms) [17].

Increases in QTc generally occurred within the first 8 weeks, stabilizing by 24 weeks in pooled data from the two Phase 2 studies. No episodes of Torsades de points (TdP) were observed in any of the three studies to date, although one death in the bedaquiline group was due to myocardial infarction.

\section{DEATHS}

In the available studies, the mortality among patients treated with bedaquiline was significantly higher than with placebo. Pooled analysis of the first two Phase 2 studies revealed that 12 of 102 subjects (11.8\%) died after taking bedaquiline, while only four of 105 subjects (3.8\%) taking placebo died. Of the deaths in the bedaquiline group, seven died during the trial and five died after withdrawing prematurely. Of the deaths in the placebo group, one died during the trial and three died after withdrawing prematurely. Deaths in the bedaquiline group, for subjects in the first two studies, occurred between 2 days and 911 days (median 386 days) after the last dose. The timing and cause of reported deaths from the three studies are shown in Table 7 . Three of the 12 deaths in the second Phase 2 study were associated with grade 3 or grade 4 liver function test abnormalities or liver-related adverse events [15]. Deaths were not associated with any pretreatment characteristics.

In the third Phase 2 study, for which final outcomes have not yet been reported, 16 of 233 subjects (6.9\%) died prior to the cut-off time for reporting to the US FDA. Of these deaths, four were among individuals who had withdrawn from the trial. Among those who attended follow-up, deaths occurred between 12 days and 685 days (median 376 days) after the last bedaquiline dose [17].

These deaths were not considered by the investigators to have been related to bedaquiline, and the QTc was not $\geq 500 \mathrm{~ms}$ or associated with a change of $>60 \mathrm{~ms}$ from baseline. There were also neither significant differences in baseline characteristics nor electrocardiogram (ECG) changes to explain the findings.

\section{DISCUSSION}

\section{Effectiveness of Bedaquiline}

It is premature to draw any conclusions regarding the effectiveness of bedaquiline as an adjunct to routine therapy for MDR-TB. The paucity of published clinical data supports a cautious approach to its use.

The primary end point in each of the three studies was time to 2-month culture conversion, a surrogate measure for effectiveness. Two-month culture conversion has been shown to predict non-relapsing cure in clinical trials of drug-susceptible TB [63]. However, this biomarker has poor prognostic value at the level of an individual patient [64] and has not been validated for patients with MDR-TB. Furthermore, the clinical importance of reduced time to culture conversion is unclear, as this may not necessarily correlate with ultimate cure. The findings of efficacy at 8 and 24 weeks in Phase 2 studies must, therefore, be interpreted with caution. Further controlled trials with defined clinically significant end points are required to confirm the findings of the available data. 
Table 7 Summary of 28 deaths from the three Phase 2 studies (among 336 patients allocated to bedaquiline plus OBR, and 105 allocated to OBR alone) [17]

\begin{tabular}{|c|c|c|c|c|c|c|}
\hline Number & $\begin{array}{l}\text { Days since } \\
\text { last intake of } \\
\text { BDQ }\end{array}$ & $\begin{array}{l}\text { Phase } 2 \\
\text { study }^{\mathrm{a}}\end{array}$ & $\begin{array}{l}\text { Treatment arm } \\
\text { (bedaquiline }+ \text { or } \\
\text { placebo) }\end{array}$ & $\begin{array}{l}\text { Premature } \\
\text { discontinuation/ } \\
\text { exclusion from } \\
\text { treatment }\end{array}$ & $\begin{array}{l}\text { Last culture } \\
\text { conversion } \\
\text { status }\end{array}$ & $\begin{array}{l}\text { Reported cause of } \\
\text { death }\end{array}$ \\
\hline 1 & 2 & Second & BDQ & No & Converter & Alcohol poisoning \\
\hline 2 & 12 & Third & BDQ & $\mathrm{ns}$ & $\begin{array}{l}\text { Non- } \\
\text { converter }\end{array}$ & Renal impairment \\
\hline 3 & 27 & Third & BDQ & $\mathrm{ns}$ & $\begin{array}{l}\text { Non- } \\
\text { converter }\end{array}$ & Tuberculosis \\
\hline 4 & 45 & Third & BDQ & ns & $\begin{array}{l}\text { Non- } \\
\text { converter }\end{array}$ & Tuberculosis \\
\hline 5 & 71 & Third & BDQ & ns & Converter & Lung infection \\
\hline 6 & 86 & Second & BDQ & No & Converter & $\begin{array}{l}\text { Hepatitis/hepatic } \\
\text { cirrhosis }\end{array}$ \\
\hline 7 & 105 & Second & Placebo & No & $\begin{array}{l}\text { Non- } \\
\text { converter }\end{array}$ & Hemoptysis \\
\hline 8 & 115 & First & BDQ & No & $\begin{array}{l}\text { Non- } \\
\text { converter }\end{array}$ & $\begin{array}{l}\text { Acute myocardial } \\
\text { infarction }\end{array}$ \\
\hline 9 & 262 & Second & BDQ & Yes (non-compliance) & Relapse & Tuberculosis \\
\hline 10 & 262 & Third & BDQ & ns & Converter & $\begin{array}{l}\text { Congestive cardiac } \\
\text { failure }\end{array}$ \\
\hline 11 & 267 & First & Placebo & $\begin{array}{l}\text { Yes (exclusion as } \\
\text { XDR-TB) }\end{array}$ & $\begin{array}{l}\text { Non- } \\
\text { converter }\end{array}$ & Tuberculosis \\
\hline 12 & 281 & Second & BDQ & No & Relapse & Tuberculosis \\
\hline 13 & 288 & Third & $\mathrm{BDQ}$ & ns & Relapse & Tuberculosis \\
\hline 14 & 314 & Second & BDQ & $\begin{array}{l}\text { Yes (exclusion as } \\
\text { XDR-TB) }\end{array}$ & $\begin{array}{l}\text { Non- } \\
\text { converter }\end{array}$ & Tuberculosis \\
\hline 15 & 344 & Second & BDQ & No & Relapse & Tuberculosis \\
\hline 16 & 427 & First & Placebo & $\begin{array}{l}\text { Yes (exclusion as } \\
\text { XDR-TB) }\end{array}$ & $\begin{array}{l}\text { Non- } \\
\text { converter }\end{array}$ & Tuberculosis \\
\hline 17 & 463 & Third & BDQ & ns & $\begin{array}{l}\text { Non- } \\
\text { converter }\end{array}$ & Tuberculosis \\
\hline 18 & 473 & Third & BDQ & ns & $\begin{array}{l}\text { Non- } \\
\text { converter }\end{array}$ & Hypertension \\
\hline 19 & 476 & Third & BDQ & ns & $\begin{array}{l}\text { Non- } \\
\text { converter }\end{array}$ & $\begin{array}{l}\text { Pyopneumothorax/ } \\
\text { respiratory failure }\end{array}$ \\
\hline 20 & 479 & Third & BDQ & ns & Converter & Hemoptysis \\
\hline
\end{tabular}


Table 7 continued

\begin{tabular}{|c|c|c|c|c|c|c|}
\hline Number & $\begin{array}{l}\text { Days since } \\
\text { last intake of } \\
\text { BDQ }\end{array}$ & $\begin{array}{l}\text { Phase } 2 \\
\text { study }^{a}\end{array}$ & $\begin{array}{l}\text { Treatment arm } \\
\text { (bedaquiline }+ \text { or } \\
\text { placebo) }\end{array}$ & $\begin{array}{l}\text { Premature } \\
\text { discontinuation/ } \\
\text { exclusion from } \\
\text { treatment }\end{array}$ & $\begin{array}{l}\text { Last culture } \\
\text { conversion } \\
\text { status }\end{array}$ & $\begin{array}{l}\text { Reported cause of } \\
\text { death }\end{array}$ \\
\hline 21 & 504 & First & $\mathrm{BDQ}$ & $\begin{array}{l}\text { Yes (exclusion as } \\
\text { XDR-TB) }\end{array}$ & $\begin{array}{l}\text { Non- } \\
\text { converter }\end{array}$ & Tuberculosis \\
\hline 22 & 513 & Second & BDQ & No & Converter & $\begin{array}{l}\text { Septic shock/ } \\
\text { peritonitis }\end{array}$ \\
\hline 23 & 556 & Second & BDQ & No & Converter & $\begin{array}{l}\text { Cerebrovascular } \\
\text { accident }\end{array}$ \\
\hline 24 & 632 & Third & BDQ & ns & Converter & Tuberculosis \\
\hline 25 & 685 & Third & $\mathrm{BDQ}$ & ns & $\begin{array}{l}\text { Non- } \\
\text { converter }\end{array}$ & $\begin{array}{l}\text { Cardiac arrest, } \\
\text { pneumonia }\end{array}$ \\
\hline 26 & 709 & Second & Placebo & Yes (non-compliance) & $\begin{array}{l}\text { Non- } \\
\text { converter }\end{array}$ & Tuberculosis \\
\hline 27 & 787 & Second & BDQ & Yes (non-compliance) & $\begin{array}{l}\text { Non- } \\
\text { converter }\end{array}$ & Tuberculosis \\
\hline 28 & 911 & Second & BDQ & $\begin{array}{l}\text { Yes (increased } \\
\text { transaminase) }\end{array}$ & Relapse & $\begin{array}{l}\text { Motor vehicle } \\
\text { accident }\end{array}$ \\
\hline
\end{tabular}

Source: information from manufacturer's submission to US FDA [17]. Data for mortality for incomplete trials are given up to the reporting cut-off date specified in the manufacturer's submission

$B D Q$ bedaquiline, FD $A$ US Food and Drugs Administration, $n s$ not stated, $O B R$ optimized background regimen, $X D R-T B$ extensively drug-resistant tuberculosis

a First study: Study C208 (Stage 1); Second study: Study C208 (Stage 2); Third study: Study C209

The available studies have a number of other weaknesses. In the first Phase 2 study [17-19], the reported rate of 8 -week culture conversion in the control population was surprisingly low (only $8.7 \%$ ), much less than that typically seen with standard treatment of MDR-TB [5, 65]. This raises concerns about the comparability of the control group, although given the small study population this may have occurred by chance. The high rate of discontinuation from both arms of this study is also concerning (54\% in placebo, $44 \%$ in bedaquiline groups by 2 years, with half withdrawing within the first 6 months). This emphasizes the challenges of MDR-TB treatment more generally.
The available evidence should be generalized with caution beyond the patient population involved in the available studies: patients with smear microscopy positive for acid fast bacilli with MDR-TB or pre-XDR-TB, aged between 18 years and 65 years. Until additional studies are performed, the effectiveness of the drug to treat MDR-TB in children or the elderly is uncertain. The mean body mass index of patients in the available studies was low, so findings may also not apply to obese populations. Further studies in this group are particularly important, given the significant levels of drug uptake into peripheral tissues, and its very long half-life. Data about the use of this drug in 
women who are pregnant, or lactating, and among patients with severe kidney disease or severe hepatic impairment are also lacking.

\section{Acquired Drug Resistance with Bedaquiline}

An important problem in the treatment of drugresistant TB is that inadequate anti-TB therapy may lead to acquired drug resistance. Adding bedaquiline may potentially reduce the likelihood that more highly resistant isolates will be selected. There are some data from the available studies to support this supposition.

In the first Phase 2 study, five of 21 patients (23.8\%) with available baseline sensitivities acquired additional second-line drug resistance during the study, compared to one patient in the bedaquiline group [19]. In the second Phase 2 study, two of 10 subjects (20\%) taking bedaquiline acquired resistance to one or more additional drugs, compared to 14 of 27 (52\%) taking placebo [17]. However, the rate of acquired drug resistance was substantially higher in the third, uncontrolled, Phase 2 study, where 7 of 17 subjects taking bedaquiline (41\%) acquired additional drug resistance [17]. The reason for the differences in acquired resistance between the first two and the third studies is not clear. However, it will be important that proper monitoring for acquired drug resistance is undertaken as bedaquiline is used more widely.

\section{Safety of Bedaquiline}

The safety profile of bedaquiline requires ongoing close scrutiny. Of particular concern, there was a substantially higher mortality rate among patients taking bedaquiline and OBRs than those taking OBRs alone [17]. There is no clear explanation for the difference in mortality from the initial analyses. It is reassuring that most deaths in the bedaquiline arm were attributable to progression of $\mathrm{TB}$, and did not occur during bedaquiline therapy. Further, the rate of mortality in the bedaquiline group was close to the rate of $15 \%$ recently reported in a meta-analysis of MDR-TB treatment outcomes [5]. However, the significant mortality difference between the bedaquiline group and control group warrants careful ongoing attention. For this reason, the US FDA has applied a 'Black Box' warning to the drug.

The increased incidence of QT prolongation among patients taking bedaquiline compared to placebo raises important concerns about cardiac toxicity of the drug. Prolongation of the QT segment on a patient's ECG, when corrected for variability due to heart rate (QTc), reflects a delay in cardiac repolarization that may be a risk factor for a potentially fatal arrhythmia called TdP. A mean QTc increase of $5 \mathrm{~ms}$ compared to a placebo group is considered of concern to regulators [66]. The mean increase for bedaquiline was $7.7 \mathrm{~ms}$ [67]. In individual patients, a measured QTc duration of more than $500 \mathrm{~ms}$, or an increase of $>60 \mathrm{~ms}$, is considered worrisome [67]. Despite no serious cardiac arrhythmias being reported during or after treatment in the available studies, the finding does warrant careful monitoring of patients taking the drug. In order to identify patients at risk of TdP, baseline measurement QTc and regular serial ECGs should be performed, as well as serum potassium, calcium, and magnesium at baseline. Patients should be carefully selected, and the use of bedaquiline avoided if the baseline QTc is $>450 \mathrm{~ms}$ or if they have a family history of heart failure. ECGs should be repeated during treatment, and the drug should be ceased immediately if the QT segment is $>500 \mathrm{~ms}$ or if a potentially fatal arrhythmia occurs. 
Other drugs that prolong the QT segment may amplify the risk of arrhythmias when used in combination with bedaquiline [68]. However, there is limited trial evidence evaluating the coadministration of bedaquiline with other drugs. A Phase 1 study showed increases in QTc with ketoconazole and bedaquiline, and the third Phase 2 study demonstrated higher QTc duration in patients with clofazamine [17]. Consequently, caution is recommended when using drugs that may prolong the QT interval. Drugs that should be avoided with bedaquiline include anti-arrhythmic drugs (such as class Ia/III agents' sotalol, dofetilide, and quinidine) and several classes of antibiotics including macrolides, imidazole anti-fungal cells, and clofazimine. Fluoroquinolones have also been associated with an increased incidence of serious arrhythmias, with variation between different agents. Recent studies have suggested that arrhythmias may be more common for moxifloxacin [69] and gatifloxacin [70] than other quinolones; however, cardiac toxicity appears to be a general class effect of quinolone antibiotics. Consequently, careful cardiac monitoring should be undertaken in further studies where bedaquiline is given in combination with any other agents that may prolong the QT segment.

Liver function abnormalities were also more common in the bedaquiline group, suggesting that the drug must be used with great caution in patients with liver disease. Although several of the reported deaths in the studies involved liver function test abnormalities, it was not certain that bedaquiline caused these changes. Based on current evidence, all patients' liver function tests should be monitored closely throughout treatment, particularly when bedaquiline is coadministered with other drugs associated with liver toxicity (in particular pyrazinamide) [71]. The authors suggest that, as with first-line $\mathrm{TB}$ drugs, the threshold of transaminases more than five times the upper limit of normal, or more than three times accompanied by symptoms of liver toxicity, should lead to immediate cessation of bedaquiline. In light of the long half-life, monitoring should be continued after cessation of the drug.

Considerable caution must also be exercised when prescribing drugs that modulate the enzyme CYP3A4 that primarily metabolizes bedaquiline. Patients with MDR-TB often receive drugs that act as CYP3A4 inhibitors (such as protease inhibitors, macrolide antibiotics, and some calcium channel blockers) [72] or inducers (such as rifampicin, efavirenz, nevirapine, glucocorticoids, and some anti-convulsants). A range of environmental, physiological, and genetic factors may also influence CYP3A4 metabolism [73]. Therefore, particular caution is needed for patients being treated with bedaquiline, particularly where other drugs are prescribed for HIV co-infection, TB meningitis, and treatment of other comorbidities.

The finding of drug-induced phospholipidosis (DIP) in pre-clinical studies of bedaquiline [19] may be relevant to some of the drug's observed toxicities. This process involves the accumulation of phospholipids and the drug within the lysosomes of any peripheral tissues, such as the liver, lungs, and kidneys [74]. DIP has been observed to occur for a number of other cationic amphiphilic drugs commonly used in clinical practice, including amiodarone, azithromycin, gentamicin, sertraline, and clozapine [67, 74]. For some drugs, such as amiodarone and fluoxetine, DIP has been associated with clinically relevant toxicity [67, 74]; however, there is ongoing debate whether this is relevant to other drugs. The accumulation of the drug in the tissues associated with DIP may explain the long half-life of bedaquiline. In 
animal studies of other drugs, the cellular changes of DIP have been shown to be reversible over weeks to months [74]; however, the process remains poorly understood in humans. It is possible that DIP explains the observation that cardiac toxicity is more pronounced in the patient sub-group taking clofazimine [17], although this remains to be confirmed. Until the relevance of DIP is better understood with bedaquiline, caution should be exercised when prescribing the drug with other medications that are known to cause DIP.

Given the limitations of the current clinical evidence, it is difficult to determine the risk-tobenefit ratio for use of bedaquiline in treating MDR-TB. Clearly, for patients with advanced levels of drug resistance, the potential toxicities may be justified. However, if effective alternatives are available, bedaquiline should be avoided until further data become available.

\section{Programmatic Issues in the Use of Bedaquiline}

Given the importance of preserving effective treatments for drug-resistant $\mathrm{TB}$, bedaquiline must be carefully protected so that drug resistance does not become widespread. Particularly in settings where MDR-TB and XDR-TB are highly prevalent, the use of bedaquiline must be carefully controlled. Offlabel use in the private sector should also be avoided. Strong collaboration between the pharmaceutical industry, government regulators, National TB Programs, and other stakeholders will be essential to minimize the risk of drug resistance occurring. Appropriate management of supply chain, monitoring of compliance, and preventing off-label use will be important in its effective implementation.

Routine programmatic monitoring and reporting of adverse events must also be a high priority. Outside of the carefully controlled research setting, it will be essential to inculcate a culture of careful monitoring for adverse events into the training and evaluation of staff. Monitoring for QT prolongation and periodic liver function testing must be available in all centers where this drug is deployed.

\section{Future Directions for Research}

There are many issues that remain to be clarified regarding the use of bedaquiline. Further study is needed to identify and develop optimal regimens for treating patients with MDR-TB using the drug. Patient eligibility must be clearly articulated, and research is particularly required among children, people living with HIV, the obese, and the elderly. Further studies examining the clinical significance of druginduced DIP must also be undertaken [75]. In the future, the drug may also be considered in drug susceptible disease, or for the treatment of non-TB mycobacteria; however, there is currently insufficient trial evidence in these populations.

\section{CONCLUSION}

Bedaquline is a member of a novel class of anti-TB drugs that has shown promise in early clinical trials using surrogate end-points of efficacy. Before its widespread use can be recommended, further studies are required to evaluate the long-term treatment outcomes, such as the rate of cure and treatment failure and relapse after a full course of MDR therapy. Careful evaluation of adverse events is required as the drug is used more widely, particularly monitoring for hepatotoxicity and cardiotoxicity. Pharmacological interactions must also be considered carefully. In light of the small number of available studies, bedaquiline should only be used in carefully monitored research 
settings. While this new drug may become a valuable player in the armamentarium used to tackle drug-resistant $\mathrm{TB}$, its risks and benefits must first be better understood.

\section{ACKNOWLEDGMENTS}

This project was supported by the National Health and Medical Research Council of Australia, APP1054107. Dr Menzies is the guarantor for this article, and takes responsibility for the integrity of the work as a whole.

Conflict of interest. Gregory J. Fox declares no conflict of interest. Dick Menzies declares no conflict of interest.

Open Access. This article is distributed under the terms of the Creative Commons Attribution Noncommercial License which permits any noncommercial use, distribution, and reproduction in any medium, provided the original author(s) and the source are credited.

\section{REFERENCES}

1. World Health Organization. Global tuberculosis control 2012. Geneva: 2012. http://www.who.int/ tb/publications/global_report/en/. Accessed on 1 May 2013.

2. World Health Organization. Treatment of tuberculosis guidelines. Geneva: 2010. http:// www.who.int/tb/features_archive/new_treatment_ guidelines_may2010/en/index.html. Accessed on 1 May 2013.

3. Keshavjee S, Farmer PE. Tuberculosis, drug resistance, and the history of modern medicine. New Engl J Med. 2012;367:931-6.

4. World Health Organization. Guidelines for the programmatic management of drug-resistant tuberculosis. Geneva 2011. http://whqlibdoc.who. int/publications/2011/9789241501583_eng.pdf. Accessed on 1 May 2013.
5. Ahuja SD, Ashkin D, Avendano M, et al. Multidrug resistant pulmonary tuberculosis treatment regimens and patient outcomes: an individual patient data meta-analysis of 9,153 patients. PLoS Med. 2012;9:e1001300.

6. Orenstein EW, Basu S, Shah NS, et al. Treatment outcomes among patients with multidrug-resistant tuberculosis: systematic review and meta-analysis. Lancet Infect Dis. 2009;9:153-61.

7. Johnston JC, Shahidi NC, Sadatsafavi M, Fitzgerald JM. Treatment outcomes of multidrug-resistant tuberculosis: a systematic review and metaanalysis. PLoS One. 2009;4:e6914.

8. Migliori GB, Sotgiu G, Gandhi NR, et al. The collaborative group for meta-analysis of individual patient data in MDR-TB. Drug resistance beyond XDR-TB: results from a large individual patient data meta-analysis. Eur Respir J. 2013;42:169-79.

9. The Stop TB Partnership. The Global Plan to Stop TB 2011-2015. Geneva 2010. http://www.stoptb. org/assets/documents/global/plan/TB_GlobalPlan ToStopTB2011-2015.pdf. Accessed on 1 May 2013.

10. United States Food and Drug Administration. 2012. http://www.fda.gov/NewsEvents/Newsroom/Press Announcements/ucm333695.htm. Accessed on 1 May 2013.

11. World Health Organization. The use of bedaquiline in the treatment of multidrug-resistant tuberculosis. Interim policy guidance. http://www. who.int/tb/challenges/mdr/bedaquiline/en/index. html. Accessed on 1 May 2013.

12. Avorn J. Approval of a tuberculosis drug based on a paradoxical surrogate measure. JAMA. 2013; 309:1349-50.

13. Cohen J. Infectious disease. Approval of novel TB drug celebrated-with restraint. Science. 2013;339: 130 .

14. Andries K, Verhasselt P, Guillemont J, et al. A diarylquinoline drug active on the ATP synthase of Mycobacterium tuberculosis. Science. 2005;307: 223-7.

15. US Food and Drug Administration. Briefing Package: NDA 204-384: Sirturo. 2012. http://www. fda.gov/downloads/AdvisoryCommittees/Commit teesMeetingMaterials/Drugs/Anti-InfectiveDrugs AdvisoryCommittee/UCM329258.pdf. Accessed on 1 May 2013.

16. Koul A, Vranckx L, Dendouga $\mathrm{N}$, et al. Diarylquinolines are bactericidal for dormant mycobacteria as a result of disturbed ATP homeostasis. J Biol Chem. 2008;283:25273-80. 
17. Janssen Briefing Document. TMC207 (bedaquiline): Treatment of patients with MDR-TB: NDA 204-384. US Food and Drug Administration Website. 2012. http://www.fda.gov/downloads/AdvisoryCommittees/ CommitteesMeetingMaterials/Drugs/Anti-Infective DrugsAdvisoryCommittee/UCM329260.pdf. Accessed on 1 May 2013.

18. Diacon AH, Pym A, Grobusch M, et al. The diarylquinoline TMC207 for multidrug-resistant tuberculosis. N Engl J Med. 2009;360: 2397-405.

19. Diacon AH, Donald PR, Pym A, et al. Randomized pilot trial of eight weeks of bedaquiline (TMC207) treatment for multidrug-resistant tuberculosis: long-term outcome, tolerability, and effect on emergence of drug resistance. Antimicrob Agents Chemother. 2012;56:3271-6.

20. Saga Y, Motoki R, Makino S, Shimizu Y, Kanai M, Shibasaki M. Catalytic asymmetric synthesis of R207910. J Am Chem Soc. 2010;132:7905-7.

21. Biukovic G, Basak S, Manimekalai MS, et al. Variations of subunit varepsilon of the Mycobacterium tuberculosis F1Fo ATP synthase and a novel model for mechanism of action of the tuberculosis drug TMC207. Antimicrob Agents Chemother. 2013;57:168-76.

22. Haagsma AC, Podasca I, Koul A, et al. Probing the interaction of the diarylquinoline TMC207 with its target mycobacterial ATP synthase. PLoS One. 2011;6:e23575.

23. Guillemont J, Meyer C, Poncelet A, Bourdrez X, Andries K. Diarylquinolines, synthesis pathways and quantitative structure-activity relationship studies leading to the discovery of TMC207. Future Med Chem. 2011;3:1345-60.

24. Upadhayaya RS, Vandavasi JK, Kardile RA, et al. Novel quinoline and naphthalene derivatives as potent antimycobacterial agents. Eur J Med Chem. 2010;45:1854-67.

25. Haagsma AC, Abdillahi-Ibrahim R, Wagner MJ, et al. Selectivity of TMC207 towards mycobacterial ATP synthase compared with that towards the eukaryotic homologue. Antimicrob Agents Chemother. 2009;53:1290-2.

26. Koul A, Dendouga N, Vergauwen $\mathrm{K}$, et al. Diarylquinolines target subunit c of mycobacterial ATP synthase. Nat Chem Biol. 2007;3:323-4.

27. de Jonge MR, Koymans LH, Guillemont JE, Koul A, Andries K. A computational model of the inhibition of Mycobacterium tuberculosis ATPase by a new drug candidate R207910. Proteins. 2007;67:971-80.
28. Petrella S, Cambau E, Chauffour A, Andries K, Jarlier V, Sougakoff W. Genetic basis for natural and acquired resistance to the diarylquinoline R207910 in mycobacteria. Antimicrob Agents Chemother. 2006;50:2853-6.

29. Gaurrand S, Desjardins S, Meyer C, et al. Conformational analysis of r207910, a new drug candidate for the treatment of tuberculosis, by a combined NMR and molecular modeling approach. Chem Biol Drug Des. 2006;68:77-84.

30. Segala E, Sougakoff W, Nevejans-Chauffour A, Jarlier V, Petrella S. New mutations in the mycobacterial ATP synthase: new insights into the binding of the diarylquinoline TMC207 to the ATP synthase C-ring structure. Antimicrob Agents Chemother. 2012;56:2326-34.

31. Huitric E, Verhasselt P, Koul A, Andries K, Hoffner S, Andersson DI. Rates and mechanisms of resistance development in Mycobacterium tuberculosis to a novel diarylquinoline ATP synthase inhibitor. Antimicrob Agents Chemother. 2010;54:1022-8.

32. Rouan MC, Lounis $\mathrm{N}$, Gevers $\mathrm{T}$, et al. Pharmacokinetics and pharmacodynamics of TMC207 and its $N$-desmethyl metabolite in a murine model of tuberculosis. Antimicrob Agents Chemother. 2012;56:1444-51.

33. Lounis N, Gevers T, Van Den Berg J, Andries K. Impact of the interaction of R207910 with rifampin on the treatment of tuberculosis studied in the mouse model. Antimicrob Agents Chemother. 2008;52:3568-72.

34. Ibrahim M, Andries K, Lounis N, et al. Synergistic activity of R207910 combined with pyrazinamide against murine tuberculosis. Antimicrob Agents Chemother. 2007;51:1011-5.

35. Zhang T, Li SY, Williams KN, Andries $\mathrm{K}$, Nuermberger EL. Short-course chemotherapy with TMC207 and rifapentine in a murine model of latent tuberculosis infection. Am J Respir Crit Care Med. 2011;184:732-7.

36. Veziris N, Ibrahim M, Lounis N, Andries K, Jarlier V. Sterilizing activity of second-line regimens containing TMC207 in a murine model of tuberculosis. PLoS One. 2011;6:e17556.

37. Tasneen R, Li SY, Peloquin CA, et al. Sterilizing activity of novel TMC207- and PA-824-containing regimens in a murine model of tuberculosis. Antimicrob Agents Chemother. 2011;55:5485-92.

38. Shang S, Shanley CA, Caraway ML, et al. Activities of TMC207, rifampin, and pyrazinamide against Mycobacterium tuberculosis infection in guinea pigs. Antimicrob Agents Chemother. 2011;55:124-31. 
39. Andries K, Gevers T, Lounis N. Bactericidal potencies of new regimens are not predictive of their sterilizing potencies in a murine model of tuberculosis. Antimicrob Agents Chemother. 2010;54:4540-4.

40. Veziris N, Ibrahim M, Lounis N, et al. A once-weekly R207910-containing regimen exceeds activity of the standard daily regimen in murine tuberculosis. Am J Respir Crit Care Med. 2009;179:75-9.

41. Ibrahim M, Truffot-Pernot C, Andries K, Jarlier V, Veziris N. Sterilizing activity of R207910 (TMC207)-containing regimens in the murine model of tuberculosis. Am J Respir Crit Care Med. 2009;180:553-7.

42. Lenaerts AJ, Hoff D, Aly S, et al. Location of persisting mycobacteria in a Guinea pig model of tuberculosis revealed by $\mathrm{r} 207910$. Antimicrob Agents Chemother. 2007;51:3338-45.

43. Lounis N, Veziris N, Chauffour A, Truffot-Pernot C, Andries K, Jarlier V. Combinations of R207910 with drugs used to treat multidrug-resistant tuberculosis have the potential to shorten treatment duration. Antimicrob Agents Chemother. 2006;50:3543-7.

44. Upadhayaya RS, Lahore SV, Sayyed AY, Dixit SS, Shinde PD, Chattopadhyaya J. Conformationallyconstrained indeno[2,1-c]quinolines-a new class of anti-mycobacterial agents. Org Biomol Chem. 2010;8:2180-97.

45. Reddy VM, Einck L, Andries K, Nacy CA. In vitro interactions between new antitubercular drug candidates SQ109 and TMC207. Antimicrob Agents Chemother. 2010;54:2840-6.

46. Diacon AH, Maritz JS, Venter A, et al. Time to detection of the growth of Mycobacterium tuberculosis in MGIT 960 for determining the early bactericidal activity of antituberculosis agents. Eur J Clin Microbiol Infect Dis. 2010;29:1561-5.

47. Dhillon J, Andries K, Phillips PP, Mitchison DA. Bactericidal activity of the diarylquinoline TMC207 against Mycobacterium tuberculosis outside and within cells. Tuberculosis. 2010;90:301-5.

48. Ji B, Lefrancois S, Robert J, Chauffour A, Truffot C, Jarlier V. In vitro and in vivo activities of rifampin, streptomycin, amikacin, moxifloxacin, R207910, linezolid, and PA-824 against Mycobacterium ulcerans. Antimicrob Agents Chemother. 2006;50:1921-6.

49. Sala C, Dhar N, Hartkoorn RC, et al. Simple model for testing drugs against nonreplicating Mycobacterium tuberculosis. Antimicrob Agents Chemother. 2010;54:4150-8.

50. Upadhayaya RS, Vandavasi JK, Vasireddy NR, Sharma V, Dixit SS, Chattopadhyaya J. Design, synthesis, biological evaluation and molecular modelling studies of novel quinoline derivatives against Mycobacterium tuberculosis. Bioorg Med Chem. 2009;17:2830-41.

51. Lounis N, Gevers T, Van den Berg J, Vranckx L, Andries K. ATP synthase inhibition of Mycobacterium avium is not bactericidal. Antimicrob Agents Chemother. 2009;53:4927-9.

52. Gelber R, Andries $\mathrm{K}$, Paredes RM, Andaya CE, Burgos J. The diarylquinoline R207910 is bactericidal against Mycobacterium leprae in mice at low dose and administered intermittently. Antimicrob Agents Chemother. 2009;53:3989-91.

53. Ji B, Chauffour A, Andries K, Jarlier V. Bactericidal activities of R207910 and other newer antimicrobial agents against Mycobacterium leprae in mice. Antimicrob Agents Chemother. 2006;50:1558-60.

54. Huitric E, Verhasselt P, Andries K, Hoffner SE. In vitro antimycobacterial spectrum of a diarylquinoline ATP synthase inhibitor. Antimicrob Agents Chemother. 2007;51:4202-4.

55. Rustomjee R, Diacon AH, Allen J, et al. Early bactericidal activity and pharmacokinetics of the diarylquinoline $\mathrm{TMC} 207$ in treatment of pulmonary tuberculosis. Antimicrob Agents Chemother. 2008;52:2831-5.

56. Diacon AH, Dawson R, Von Groote-Bidlingmaier F, et al. Randomized dose-ranging study of the 14-day early bactericidal activity of bedaquiline (TMC207) in patients with sputum microscopy smear-positive pulmonary tuberculosis. Antimicrob Agents Chemother. 2013;57:2199-203.

57. Dooley KE, Park JG, Swindells S, ACTG 5267 Study Team, et al. Safety, tolerability, and pharmacokinetic interactions of the antituberculous agent TMC207 (bedaquiline) with efavirenz in healthy volunteers: AIDS Clinical Trials Group Study A5267. J Acquir Immune Defic Syndr. 2012;59:455-62.

58. Svensson EM, Aweeka F, Park JG, Marzan F, Dooley $\mathrm{KE}$, Karlsson MO. Model-based estimates of the effects of efavirenz on bedaquiline pharmacokinetics and suggested dose adjustments for patients co-infected with HIV and tuberculosis. Antimicrob Agents Chemother. 2013;57:2780-7.

59. Wallis RS, Jakubiec W, Mitton-Fry M, et al. Rapid evaluation in whole blood culture of regimens for XDR-TB containing PNU-100480 (sutezolid), TMC207, PA-824, SQ109, and pyrazinamide. PLoS One. 2012;7:e30479.

60. Diacon AH, Dawson R, von Groote-Bidlingmaier F, et al. 14-Day bactericidal activity of PA-824, 
bedaquiline, pyrazinamide, and moxifloxacin combinations: a randomised trial. Lancet. 2012;380:986-93.

61. Laserson KF, Thorpe LE, Leimane V, et al. Speaking the same language: treatment outcome definitions for multidrug-resistant tuberculosis. Int $\mathrm{J}$ Tuberc Lung Dis. 2005;9:640-5.

62. Sidak Z. Confidence regions for the means of multivariate normal distributions. J Am Stat Assoc. 1967;62:626-33.

63. Wallis RS, Pai M, Menzies D, et al. Biomarkers and diagnostics for tuberculosis: progress, needs, and translation into practice. Lancet. 2010;375: 1920-37.

64. Horne DJ, Royce SE, Gooze L, et al. Sputum monitoring during tuberculosis treatment for predicting outcome: systematic review and metaanalysis. Lancet Infect Dis. 2010;10:387-94.

65. Gler MT, Skripconoka V, Sanchez-Garavito E, et al. Delamanid for multidrug-resistant pulmonary tuberculosis. N Engl J Med. 2012;366:2151-60.

66. Food and Drug Administration. E14 Clinical evaluation of QT/QTc interval prolongation and proarrhythmic potential for non-antiarrhythmic drugs-questions and answers (R1). http://www. fda.gov/Drugs/GuidanceComplianceRegulatory Information/Guidances/ucm323656.htm. Accessed on 28 May 2013.

67. Muehlbacher M, Tripal P, Roas F, Kornhuber J. Identification of drugs inducing phospholipidosis by novel in vitro data. Chem Med Chem. 2012;7: 1925-34.
68. Owens RC Jr, Nolin TD. Antimicrobial-associated QT interval prolongation: pointes of interest. Clin Infect Dis. 2006;43:1603-11.

69. Pugi A, Longo L, Bartoloni A, et al. Cardiovascular and metabolic safety profiles of the fluoroquinolones. Expert Opin Drug Saf. 2012;11: 53-69.

70. Lapi F, Wilchesky M, Kezouh A, Benisty JI, Ernst P, Suissa S. Fluoroquinolones and the risk of serious arrhythmia: a population-based study. Clin Infect Dis. 2012;55:1457-65.

71. Shih TY, Pai CY, Yang P, Chang WL, Wang NC, Hu OY. A novel mechanism underlies the hepatotoxicity of pyrazinamide. Antimicrob Agents Chemother. 2013;57:1685-90.

72. Zhou S, Chan E, Li X, Huang M. Clinical outcomes and management of mechanism-based inhibition of cytochrome P450 3A4. Ther Clin Risk Manag. 2005;1:3-13.

73. Klein K, Zanger UM. Pharmacogenomics of cytochrome P450 3A4: recent progress toward the "Missing Heritability" problem. Front Genet. 2013;4:12.

74. Reasor MJ, Hastings KL, Ulrich RG. Drug-induced phospholipidosis: issues and future directions. Expert Opin Drug Saf. 2006;5:567-83.

75. Shayman JA, Abe A. Drug induced phospholipidosis: an acquired lysosomal storage disorder. Biochim Biophys Acta. 2013;1831:602-11. 